\title{
Toxicity effects of amlodipine on the body weight and sperm count in adult wistar rats
}

\author{
Huthman Ibrahim Oluwaseun ${ }^{1, ~ *, ~ I b r a h i m ~ B i l i k i s ², ~ H u t h m a n ~ A d e b u k o l a ~ S e l i m o t ~}{ }^{3}$, \\ Otulana Jibril ${ }^{1}$ \\ ${ }^{1}$ Department of Anatomy, Olabisi Onabanjo University, Ogun State Nigeria \\ ${ }^{2}$ Department of Pharmacy, Federal Medical Centre Umuahia, Abia State, Nigeria \\ ${ }^{3}$ Department of Analytical Chemistry, Federal Institute of Industrial Research Oshodi (FIIRO), Lagos state, Nigeria
}

Email address:

huthmanseun@yahoo.com(H. I. Oluwaseun)

\section{To cite this article:}

Huthman Ibrahim Oluwaseun, Ibrahim Bilikis, Huthman Adebukola Selimot, Otulana Jibril. Toxicity Effects of Amlodipine on the Body Weight and Sperm Count in Adult Wistar Rats. American Journal of Clinical and Experimental Medicine. Vol. 1, No. 1, 2013, pp. 1-4. doi: $10.11648 /$ j.ajcem.20130101.11

\begin{abstract}
Amlodipine is one of the calcium channel blocker class of antihypertensive used in the treatment of hypertension. Amlodipine is widely used in Nigeria today as an antihypertensive although the side effect on health has been reported, based on researches done. This study was carried out to appraise the toxicity effects of Amlodipine on the body weight and sperm count in Adult Wistar rats. The rats were divided into 3 groups: group 1 was given normal saline while group 2 and 3 were administered with $0.052 \mathrm{mg} / \mathrm{g} / \mathrm{BW}$ and $0.104 \mathrm{mg} / \mathrm{g} / \mathrm{BW}$ of amlodipine respectively. Our preliminary observations showed that Amlodipine did not have any effect on the body weight but lead to a decrease in sperm count. These effects were totally different from the rats used in the control group and by these preliminary observations, toxic dose of Amlodipine has been shown to lead to infertility in rats.
\end{abstract}

Keywords: Amlodipine, Hypertension, Sperm Count, Infertility, Body Weight

\section{Introduction}

Amlodipine (as besylate, mesylate or maleate) is a longacting calcium channel blocker (dihydropyridine class) used as an anti-hypertensive and in the treatment of angina[1]. Like other calcium channel blockers, amlodipine acts by relaxing the smooth muscle in the arterial wall, decreasing peripheral resistance and hence reducing blood pressure; in angina it increases blood flow to the heart muscle.

Seminiferous tubules produce male reproductive cells: spermatozoa at a daily rate of about $20,000,000$ while adult interstitial cells also known as leydig cells secrete testicular androgens. Each testes has about 250-1000 seminiferous tubules that measure about $150-250 \mathrm{uM}$ in diameter and 30 $70 \mathrm{~cm}$ in length. The combined length of the tubule of one testes is about $250 \mathrm{~m}[2]$. The tubules are convoluted and have the form of loops at whose ends; the lumen narrows and continues in short segment known as straight tubules or tubuli recti that connect the seminiferous tubules to an anastomosing labyrinth of epithelium-lined channels, the rete testis connected by 10-20 ducti efferent to the cephalic portion of epididymis. The seminiferous tubules are lined with a complex stratified epithelium called germinal or seminiferous epithelium which consists of two types of cells the sertoli or supporting cells and cells that constitute the spermatogenic lineage whose cells are stacked in 4-8 layers whose function is to produce spermatozoa and the outer wall is surrounded by a well defined basal lamina and a fibrous connecting tissue consisting of several layers of fibroblast[3].

The male gametes are called spermatozoa. The gameteproducing organs of animals are called gonads and the formation of gametes in the gonads of animals is called gametogenesis. The sperm cell consists of a head, a midpiece and a tail. The head contains the nucleus with densely coiled chromatin fibres, surrounded anteriorly by an acrosome, which contains enzymes used for penetrating the female egg. The midpiece has a central filamentous core with many mitochondria spiralled around it, used for ATP production for the journey through the female cervix, uterus and uterine tubes. The tail or "flagellum" executes the lashing movements that propel the spermatocyte. 
Hypertension (HTN) or high blood pressure is a chronic medical condition in which the blood pressure in the arteries is elevated. It is the opposite of hypotension and it is classified as either primary (essential) or secondary. About $90-95 \%$ of cases are termed "primary hypertension", which refers to high blood pressure for which no medical cause can be found[4]. The remaining $5-10 \%$ of cases (Secondary hypertension) are caused by other conditions that affect the kidneys, arteries, heart, or endocrine system. Persistent hypertension is one of the risk factors for strokes, heart attacks, heart failure and arterial aneurysm, and is a leading cause of chronic kidney failure[5].Moderate elevation of arterial blood pressure leads to shortened life expectancy. Both dietary and lifestyle changes as well as medicines can improve blood pressure control and decrease the risk of associated health complications. Hypertensive patients in the year 2000 were estimated to be nearly one billion people or $\sim 26 \%$ of the adult population have hypertension worldwide[6]. It was common in both developed (333 million ) and undeveloped (639 million) countries[6] however rates vary markedly in different regions with rates as low as $3.4 \%$ (men) and $6.8 \%$ (women) in rural India and as high as $68.9 \%$ (men) and $72.5 \%$ (women) in Poland[7]

In 1995 it was estimated that 43 million people in the United States had hypertension or were taking antihypertensive medication, almost $24 \%$ of the adult population[8]. The prevalence of hypertension in the United States is increasing and reached 29\% in 2004[9][10]. It is more common in blacks and less in whites and Mexican Americans, rates increase with age, and is greater in thesoutheastern United States. Hypertension is more prevalent in men (though menopause tends to decrease this difference) and those of low socioeconomic status[6] and also, a lot of treatments have come up for hypertension.

Considering the amount of people that will be using amlodipine as a hypertensive, it is clinically imperative that we can analyze the toxicity effects of amlodipine on the body weight and sperm count.

\section{Materials and Methods}

\subsection{Management}

24 Adult Wistar rats were obtained from the colony breed of the animal house of the Department of Anatomy, OAU, Ile-Ife. The animals were divided into three groups; two treatments and one control. In the treatment groups there were 5 rats each while the control group was assigned four rats. The rats weighed between $150 \mathrm{~g}-2560 \mathrm{~g}$ with ages ranging from 10-12 weeks. They were housed in individual cages in a room with ambient temperature. The rats were fed during the experimental procedure with standard pellet diet (Sesco Feeds Ikenne, Nigeria). The weights of the rats were taken daily.

\subsection{Drug Administration}

Amlodipine was administered orally at a dosage of $0.052 \mathrm{mg} / \mathrm{g}$ body weight and $0.104 \mathrm{mg} / \mathrm{g}$ body weight for the treated groups, once daily for 8 weeks. The control group received an equivalent volume of $0.5 \mathrm{ml}$ of normal saline. The drug was manufactured by Pfizer Pharmaceuticals. Oregun, Lagos Nigeria.

$\mathrm{N}$ : B: The actual concentration of the of the amlodipine given to each rat was obtainedfrom calculations using the average weight of the rats per group

If a $70000 \mathrm{~g}$ adult man is given $5 \mathrm{mg}$ of amlodipine

Then a $195 \mathrm{~g}$ adult rat will receive $5 \mathrm{mg}$ X $195=0.013 \mathrm{mg}$

$70000 \mathrm{Nb}-$ The normal dose is $5 \mathrm{mg} / \mathrm{kg} / \mathrm{BW}$

\subsection{Sperm Count}

$200 \mathrm{ml}$ of Monica's fluid was prepared, and then variable volumes of it were added to the crushed epididymis mixture and viewed on a hemocytometer. On the hemocytometer, the sperms that fell into the centre box and 2 of the edges of the hemocytometer were counted and then the result multiplied by 32,000 and also by the dilution factor. The readings were then recorded

\section{Results}

\subsection{Physical Observations}

In the treatment group, hair loss was observed (plate 1). Some animals also exhibited loss of locomotion and balance ( 2 and 3 ). In the control group the animals remained stable and physically normal. There was neither loss of hair nor locomotion loss.

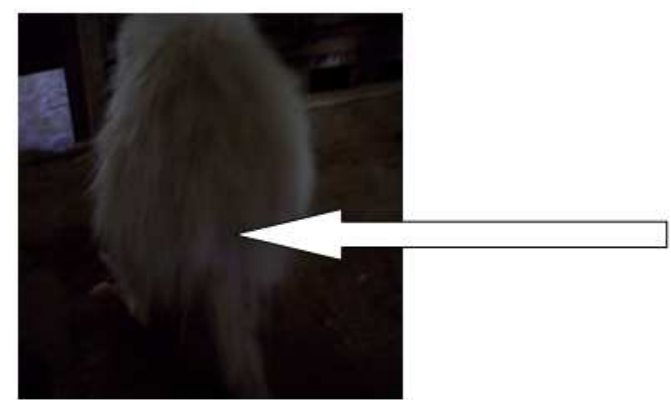

Figure 1. In the group treated with $0.052 \mathrm{mg} / \mathrm{g}$ body weight amilodipine, hair loss was observed all over the rats body after a period of 8 weeks

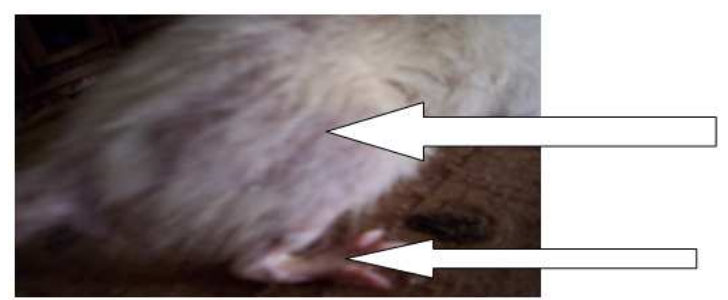

Figure 2. Also in the group treated with $0.052 \mathrm{mg} / \mathrm{g}$ body weight amilodipine, hair loss was observed all over the rats body after a period of 8 weeks 


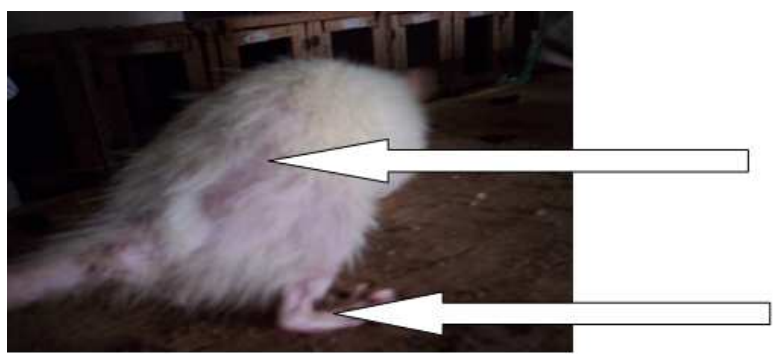

Figure 3. In the group treated with $0.104 \mathrm{mg} / \mathrm{g}$ body weight amilodipine, hair loss and locomotion loss was observed in the rat after a period of 8 weeks

\subsection{Body Weight}

Table 1. The toxicity effect of amlodipine on the body weight showed no significant effect in the weight of adult Wistar rats

\begin{tabular}{cccc}
\hline Week & $\begin{array}{c}\text { Treated 0.052mg } \\
(\mathrm{n}=5)\end{array}$ & $\begin{array}{c}\text { Treated 0.102mg } \\
(\mathrm{n}=5)\end{array}$ & $\begin{array}{c}\text { Control } \\
(\mathrm{n}=4)\end{array}$ \\
\hline 1 & $220 \mathrm{~g}$ & $225 \mathrm{~g}$ & $185 \mathrm{~g}$ \\
2 & $223 \mathrm{~g}$ & $225 \mathrm{~g}$ & $190 \mathrm{~g}$ \\
3 & $225 \mathrm{~g}$ & $230 \mathrm{~g}$ & $195 \mathrm{~g}$ \\
4 & $228 \mathrm{~g}$ & $230 \mathrm{~g}$ & $200 \mathrm{~g}$ \\
5 & $230 \mathrm{~g}$ & $233 \mathrm{~g}$ & $205 \mathrm{~g}$ \\
6 & $230 \mathrm{~g}$ & $235 \mathrm{~g}$ & $210 \mathrm{~g}$ \\
\hline
\end{tabular}

GRAPH SHOWING BODY WEIGHT

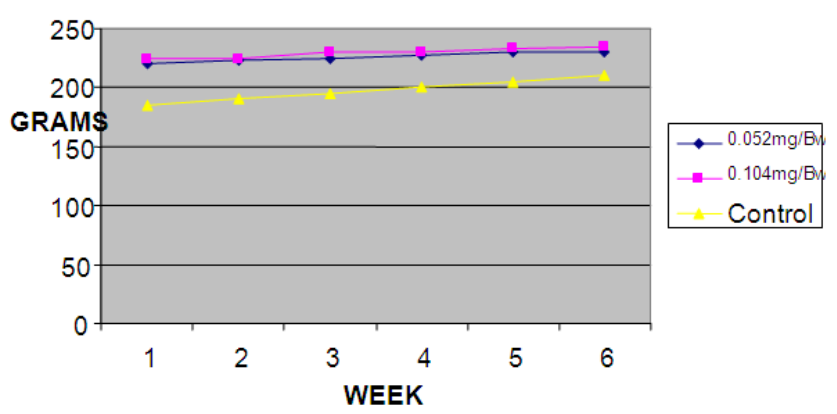

Figure 4. From the result of the body weight above, it was shown that there was not any marked increase in the body weight of the experimental as compared to the control group

\subsection{Result of Sperm Count}

Table 2. Toxicity effect of amlodipine on the sperm countshowing a decrease in sperm count in adult Wistar rats in a dose related fashion

\begin{tabular}{cccc}
\hline & $\begin{array}{c}\text { Group 1 } \\
(\text { Control })\end{array}$ & $\begin{array}{c}\text { Group 2 } \\
(0.052 \mathrm{mg} / \mathrm{G})\end{array}$ & $\begin{array}{c}\text { Group 3 } \\
(0.102 \mathrm{~g} / \mathrm{G})\end{array}$ \\
\hline RAT 1 & $19.7 \times 10^{6}$ & $1.4 \times 10^{6}$ & No Sperm Visible \\
RAT 2 & $12.0 \times 10^{6}$ & $1.3 \times 10^{6}$ & No Sperm Visible \\
RAT 3 & $8.5 \times 10^{6}$ & $1.4 \times 10^{6}$ & No Sperm Visible \\
RAT 4 & $12.1 \times 10^{6}$ & $3.3 \times 10^{6}$ & No Sperm Visible \\
AVERAGE & $13.1 \times 10^{6}$ & $1.48 \times 10^{6}$ & No Sperm Visible \\
\hline
\end{tabular}

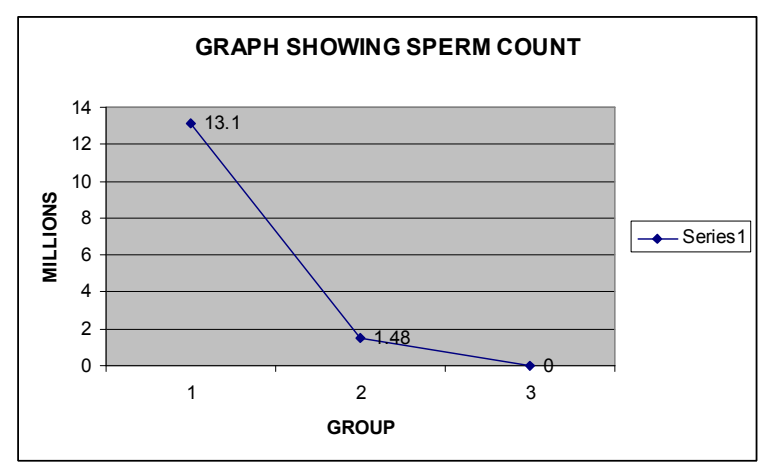

Figure 5. From the figure above it was shown that they was a marked decrease in the sperm count in rats administered with amilodipine in a dose related fashion as compared to the control

\section{Discussion}

It could be observed from the result obtained in this study that a high dose of $0.052 \mathrm{mg} / \mathrm{g} /$ bodyweight of amlodipine lead to a decrease in sperm count while a higher dose of $0.104 \mathrm{mg} / \mathrm{kg} /$ bodyweight led to total absence of sperm cells when administered daily for 8 weeks. The high doses were designed to represent human exposure to high levels of amlodipine. The results were in agreement with earlier studies which reported that administration of amlodipine led to low sperm count due to it's calcium channel blocking activities[11]; however other researches on Lorel[a brand of amlodipine] came up with findings that amlodipine did not have any effect on fertility in Wistar rats[12]. This data also collaborated with physical observation. The result further showed that the higher the dosage administered, the more effect it has on the sperm count which implied that the effects of amlodipine on sperm count was directly proportional to the dose.

Finally it was also discovered that the drug didn't have any effect on the body weight on the animals for the body weights of the experimental increased in the same fashion as that of the control.

\section{Conclusion}

This study joins other in confirming that it had an adverse effect. It can be concluded from the result of this work that high doses of amlodipine does not have any effect on the body weight but led to a decrease in sperm count when compared to the control, therefore one can conclude that high doses of amlodipine could lead to infertility in man.

It is recommended that further work should be done to elucidate the toxicity effects of amlodipine on the body weight and sperm count of male adult Wistar rats.

\section{Acknowledgements}

This is to acknowledge my colleagues in the faculty of Basic Medical Science Olabisi Onabanjo University for their support and assistance in the course of this research 


\section{References}

[1] U.S. National Library of Medicine: Drug Information Portal - Amlodipine

[2] Johnson A. D. and Gomes W.R., The testis, Vols. 1-4 Academic Press, 1970.

[3] Trainer T. D, Histology of the normal testis, Vol.11, Am J surg Pathol, 1987, pp. 797.

[4] Carretero O. A., S. Oparil, Essential hypertension. Part I: definition and etiology, Vol.3, Circulation 101, 2000, pp.329-35.

[5] Pierdomenico S.D., M. Di Nicola, A.L. Esposito, Prognostic Value of Different Indices of Blood Pressure Variability in Hypertensive Patients,Vol.22, American Journal of Hypertension, 2009, pp (8):842-7.

[6] Kearney P. M., M. Whelton, K. Reynolds, P. Muntner, P.K. Whelton, J. He, Global burden of hypertension: analysis of worldwide data, Vol.365, Lancet, 2005, pp (9455) 217-23.

[7] Kearney P. M., M. Whelton, K. Reynolds, P.K. Whelton, J. He, Worldwide prevalence of hypertension: A systematic review, Vol.22, J. Hypertens, 2004, pp (1): 11-9.
[8] Burt V. L., P. Whelton, E.J. Roccella,. Prevalence of hypertension in the US adult population. Results from the Third National Health and Nutrition Examination Survey 1991-1995, Vol.525, Hypertension, 1995, pp(3): 305-13.

[9] Burt V. L., J. A. Cutler, M. Higgins, Trends in the prevalence, awareness, treatment, and control of hypertension in the adult US population. Data from the health examination surveys, 1960 to 1991: Vol. 26, Hypertension 1995, pp(1): 60-9.

[10] Ostchega Y., C.F. Dillon, J.P. Hughes, M. Carroll, S. Yoon,. Trends in hypertension prevalence, awareness, treatment, and control in older U.S. adults: data from the National Health and Nutrition Examination Survey 1988 to 2004, Vol.55, Journal of the American Geriatrics Society, 2007 $\mathrm{pp}(7)$ : $1056-65$.

[11] Almeida S.A., J.M. Teófilo, J.A. Anselmo Franci, L.G. Brentegani, T.L. Lamano- Carvalho,. Antireproductive effect of the calcium channel blocker amlodipine in male rats, Vol. 52, Exp Toxicol Pathol. 2000 pp(4): 353-6.

[12] Source: Sandoz product information sheet 